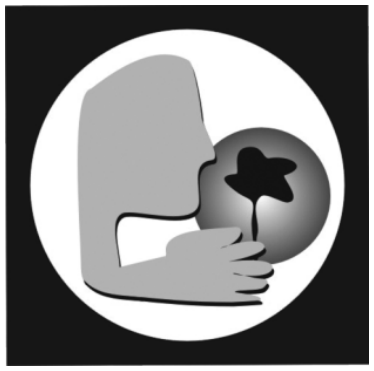

Sustentabilidade e $\mathrm{m}$ Debate

\title{
A "Insularização" dos Continentes e a Perda de Biodiversidade
}

\author{
Maira Smith ${ }^{1}$ \\ ${ }^{1}$ Doutoranda em Política e Gestão Ambiental pelo Centro de \\ Desenvolvimento Sustentável (CDS) da UnB
}

Recebido em 17.02.2010

Aceito em 28.04.2010

\section{RESENHA}

QUAMMEN, David. O canto do dodô. São Paulo: Companhia das Letras, 2008. 789p. ISBN 978-85-3591263-0. [Traduzido do original The song of the dodo: island biogeography in an age of extinctions. New York: Touchstone, 1997. 704 p. ISBN 0-684-80083-7]. Tradução de Carlos Afonso Malferrari. Mapas de Kris Ellingsen. Notas, índice remissivo e bibliografia.

É cada vez mais evidente o desafio em que vive o mundo moderno: enfrentar a onda crescente de extinção de espécies, comunidades e ecossistemas que compõem a biodiversidade, exacerbada pela atuação humana. Por conta de ações como o desmatamento, redução de habitats, introdução de espécies exóticas, homogeneização genética de recursos agrícolas, super-exploração de recursos naturais, entre outras, ambientes antes contínuos estão se tornando cada vez mais fragmentados, formando para as espécies remanescentes o que os ecólogos chamam de "ilhas de habitat" nos continentes.

A "insularização" ou o isolamento de espécies e comunidades biológicas, conseqüências da fragmentação crescente de habitats, e o resultante aumento de sua vulnerabilidade à extinção, são os temas centrais abordados no livro $O$ canto do Dodô, de David Quammen, traduzido para o português e publicado pela editora Companhia das Letras em
2008. O título original, The song of the dodo: island biogeography in an age of extinctions, remete o leitor ao exemplo do Dodô (Raphus cucullatus), uma espécie de ave agigantada que viveu nas ilhas Maurício, com características típicas de evolução e distribuição insulares, levada à extinção pela ação direta e indireta dos colonizadores portugueses e holandeses.

Quammen é um jornalista norte-americano, casado com uma ecóloga, e que se dedica entre outras coisas ao estudo e à difusão da história da biologia da conservação, disciplina científica aplicada desenvolvida recentemente para estudar a perda de biodiversidade decorrente da ação humana. Quammen é autor de outros livros de ficção e não-ficção como The Reluctant Mr. Darwin: A Intimate Portrait of Charles Darwin and the Making of His Theory of Evolution e já foi premiado com a medalha "John Burroughs" de divulgação em história natural. 


\section{A "insularização" dos continentes e a perda de biodiversidade}

Pelo fato de ser jornalista, e não um cientista especializado em biologia ou áreas afins, o autor consegue repassar conceitos técnicos relacionados à conservação da biodiversidade, em geral indigestos, de forma acessível ao público leigo. Faz isso de forma leve e bem humorada, por meio de relatos pessoais de viagens, do acompanhamento de estudos de campo e de entrevistas pessoais com pesquisadores consagrados no assunto. No livro, Quammen fala sobre sua estadia em locais como Indonésia, Maurício (local onde ocorria o dodô antes de ser extinto), Golfo da Califórnia, Galápagos, Austrália, Tasmânia, Micronésia e Brasil. Nesse último, o autor visitou projetos ligados à conservação da biodiversidade na Amazônia Central (proximidades de Manaus) e na Mata Atlântica (Minas Gerais). Em todos os locais visitados, o autor acompanhou pesquisadores de diferentes áreas da biologia. Além disso, Quammen é um apaixonado pelas ciências naturais. Acumula um grande volume de leituras sobre biologia evolutiva, biogeografia de ilhas, ecologia e biologia da conservação, usando as obras dos autores de referência em cada ramo das atividades científicas que examina. Entre os entrevistados, o autor apresenta uma lista de cientistas ilustres nas ciências biológicas, como Edward O. Wilson, Michael Soulé, Jared Diamond, Dan Simberloff, Tomas Lovejoy, entre outros.

Os relatos das viagens do autor a diversos lugares onde ocorrem e/ou se estudam extinções ou quase-extinções e uma infinidade de exemplos retirados da literatura científica ou das entrevistas com cientistas dão suporte para que o leitor se envolva e compreenda de forma aprofundada conceitos técnicos necessários para o entendimento da idéia central do livro. Essa idéia consiste em demonstrar como os estudos de biogeografia de ilhas foram fundamentais para a formulação da teoria da evolução proposta por Darwin e Wallace na segunda metade do século XIX e para a consolidação da biologia enquanto disciplina específica, diferenciada de outras ciências naturais. Foram fundamentais também para a construção recente de campos científicos mais aplicados, como a ecologia e a biologia da conservação, essa última voltada para enfrentar o grande desafio moderno de conservar e proteger a biodiversidade em um mundo cada vez mais fragmentado. Ressalte-se que a biolo- gia da conservação, principalmente a partir do estudo de ecologia teórica e da biogeografia de ilhas, é a disciplina que dá suporte para a modelagem de áreas reservadas para conservação e proteção da biodiversidade.

É particularmente interessante a ordem lógica de apresentação das informações colocada por Quammem na organização do livro, pois ela reflete detalhes históricos da construção de disciplinas como a ecologia teórica e a biologia da conservação, que dificilmente seriam tão bem exploradas se fossem apresentados por um especialista na área de ciências biológicas. Por outro lado, esse tipo de detalhe requer aprofundamento na leitura especializada e bastante conhecimento de história natural, o que não falta ao autor.

No início do livro, o termo biogeografia é definido como "a ciência que se ocupa de onde os animais e plantas estão, onde não estão e por que" (p. 17). O autor dedica um capítulo inteiro - "O homem que conhecia ilhas" - a relatos relacionados ao naturalista Alfred Russel Wallace, um dos pioneiros na observação da distribuição de espécies em ilhas e, em sua opinião, um dos maiores biogeógrafos de todos os tempos. Quammen considera uma injustiça histórica que Wallace não seja amplamente reconhecido como formulador da mais importante teoria da biologia, desenvolvida por ele e Charles Darwin - a teoria da evolução. Os dois chegaram a essa teoria na mesma época e a partir de observações sobre a distribuição de espécies em ilhas em diferentes contextos.

Quammen chama a atenção do leitor para o processo de especiação em ilhas, ou seja, o processo pelo qual uma espécie se divide em duas ou mais espécies novas, ocasionando a diversificação. Isso teria levado Darwin e Wallace a perceber que as espécies variam no espaço e no tempo, pressuposto básico da evolução. Quammen aproveita essa parte do livro para definir alguns conceitos importantes da biologia evolutiva e explicar como essa disciplina se desenvolveu na primeira metade do século XX a partir da contribuição da genética e, sobretudo, da proposição da "síntese moderna", que originou o neodarwinismo. Dentre os expoentes dessa escola de pensamento, destaca-se o ornitólogo Ernst Mayr, que na visão do autor era também um biogeógrafo de ilhas. Pelo olhar 


\section{Sustentabilidade em Debate}

de Mayr, Quammen ressalta no terceiro capítulo "Uma grandiosidade tão imensa" - a importância do isolamento geográfico, que confere a peculiaridade do processo evolutivo em ilhas, como mola propulsora da evolução. Ele cita a idéia proposta por Mayr em 1954 de que as "revoluções genéticas" ou mudanças súbitas no ambiente genético de uma população biológica estariam entre as causas principais da acelerada evolução insular.

Depois de discorrer sobre questões da biologia evolutiva, o autor dedica uma grande parte do livro ao domínio específico da biogeografia de ilhas. É interessante a forma como ele apresenta ao leitor um conjunto tão denso de informações. Por outro lado, exagera um pouco na descrição de detalhes e exemplos, o que torna a leitura por vezes cansativa. Nessa parte do livro são apresentados padrões característicos da biologia insular, incorporados pelo autor numa lista que denomina "cardápio insular". Nesse cardápio destacam-se 1) atributos relacionados às espécies como a) capacidade de dispersão, b) mudanças de tamanho (em geral associadas à ausência de predadores e/ou competidores), c) perda da capacidade de dispersão, d) endemismo (espécies que ocorrem no mesmo local onde evoluíram), e) relictualismo (espécies sobreviventes em determinado local e extintas em todos os outros locais), f) perda de adaptações defensivas (espécies que perdem ao longo da evolução características defensivas pela ausência de predadores, por exemplo), g) especiação arquipelágica (processo evolutivo no qual um ancestral comum, pelo processo de colonização e adaptação, dá origem a diferentes espécies endêmicas em distintas ilhas de um arquipélago), h) irradiação adaptativa (diversificação de espécies provenientes de um ancestral comum em uma mesma área para preencher uma ampla variedade de nichos ecológicos; e 2) atributos relacionados às comunidades biológicas: a) desarmonia e b) empobrecimento (diminuição no número de espécies que compõem a comunidade). Ao final, apresenta o último e mais importante item do cardápio insular, que é a extinção, ressaltando que as "ilhas são onde as espécies vão para morrer" (p. 281).

Para tentar explicar a importância do processo de extinção de espécies em ilhas, o autor lança mão de um capítulo - "A raridade que leva à morte" fornecendo como exemplo o emblemático caso do dodô. O que teria causado a extinção do dodô não seria apenas a ação humana direta, como a sobrecaça, mas diversas ações indiretas que levaram à raridade da espécie. Como diz Quammen, "a raridade é a précondição para a extinção". Ele classifica a raridade como perigosa, pois as populações pequenas são mais susceptíveis a tragédias determinísticas (essencialmente decorrentes de atividades humanas) e estocásticas (não previsíveis). Além disso, essas populações apresentam forte probabilidade de, no processo natural de dinâmica populacional, oscilar até zero. Dessa forma, a extinção de espécies em ilhas é muito mais freqüente que no continente. A tendência observada é de que, quanto menor a ilha, maior a incidência de extinções locais. A raridade, no entanto, não pode ser considerada igual para todas as espécies, pois a estrutura social e as características ecológicas determinam diferentes limiares de estabilidade populacional para cada espécie.

No mesmo capítulo, o autor fala sobre a modificação de ecossistemas por meio de "cascatas tróficas" - termo proposto por Jared Diamond - para explicar o encadeamento de rupturas de um nível trófico para o outro até atingir todo o sistema. O que Diamond quis dizer é que mudanças na abundância (número de indivíduos) em uma espécie podem acarretar mudanças na abundância de outras espécies, podendo levar à raridade de algumas populações que fazem parte do ecossistema. Seguindo a linha de estudos aplicados à conservação da biodiversidade, Quammen destaca os trabalhos do biólogo Michael Soulé que, no início da década de 1980, começou a pesquisar mais a fundo quais os fatores que contribuem mais ou menos para a extinção das espécies.

No campo da ecologia, uma das generalizações mais antigas segundo Quammen é a relação espécies-área, mencionada em publicações científicas desde a década de 1920. Em termos gerais, tal relação aponta que as áreas maiores sustentam mais espécies que as áreas menores. No âmbito da biogeografia, no entanto, a pergunta central permaneceu enigmática por algum tempo: "o que provoca essa relação entre espécies e área? Se a limitação da área resulta numa limitação da diversidade de espécies, como se exerce 


\section{A "insularização" dos continentes e a perda de biodiversidade}

tal limitação?” (p. 425). Quammen aponta o pesquisador Frank Preston como um dos pioneiros a teorizar questões mais específicas de ecologia de comunidades, constatando um padrão - "padrão canônico de Preston" - na distribuição de freqüência e raridade de espécies que compõem comunidades de plantas. Até então, nas palavras do autor: "a ecologia, tal como era geralmente praticada continuava sendo um empreendimento desarticulado, descritivo, não quantificado e não teórico" (p. 449). Na visão de Quammen, Preston teria contribuído com o desenvolvimento da ecologia teórica a partir do levantamento de dois tópicos que resistiram ao tempo: a) a proposição da equação matemática de Arrhenius - $S$ $=c A^{z}$ - para expressar a relação espécies-área e b) a distinção entre unidades de amostra e unidades isoladas.

Nas décadas de 1950 e 1960 alguns poucos ecólogos, como G. Evelyn Hutchinson e o seu aluno Robert MacArthur, começaram a desenvolver de forma mais incisiva uma nova forma de fazer ecologia, inserindo em seu arcabouço análises matemáticas e desenvolvendo modelos teóricos. As idéias de Preston, somadas à contribuição dessa nova abordagem matemática, ajudaram a abrir caminho para a formulação da teoria da biogeografia de ilhas, proposta por Robert MacArthur e Edward Wilson em 1967, causando uma revolução na ecologia.

Os aspectos inovadores e fundamentais apresentados nessa teoria foram: a) a explicação quantificável da relação espécies-área e o efeito da distância do continente na composição de comunidades biológicas em áreas isoladas, bem como b) a existência de um equilíbrio dinâmico na diversidade de espécies de uma determinada ilha, resultante dos processos de colonização e extinção locais. Em ilhas ou ambientes isolados, as espécies normalmente experimentam uma intensificação nos processos de migração, especiação e extinção, o que faz com que o nível de diversidade se mantenha razoavelmente constante ao longo do tempo, apesar da ocorrência de extinções. Embora o número de espécies seja relativamente estável, há nesses ambientes uma taxa elevada de substituição ou turnover de espécies, o que acarreta em modificação constante no conjunto de espécies que ali habitam, havendo sempre a renovação das comu- nidades biológicas. Com a teoria da biogeografia de ilhas, esses parâmetros podem ser medidos, experimentados e comparados, o que levou a ecologia ao rol das ciências que permitem certa previsibilidade de situações futuras.

No entanto, o fator mais importante da teoria da biogeografia de ilhas foi a percepção de que seus princípios eram aplicáveis não somente para ilhas reais, mas para fragmentos de habitats sujeitos a diferentes níveis de isolamento, cada vez mais freqüentes no mundo moderno, a partir da expansão humana em praticamente todos os ecossistemas da Terra. Com a formulação dessa teoria, os biólogos começaram a perceber que as ações do homem sobre a natureza estavam causando às espécies, comunidades e ecossistemas da biodiversidade um processo de "insularização" nos continentes.

Após a publicação da teoria, alguns ecólogos passaram a fazer experimentos em diferentes partes do mundo, fornecendo exemplos e evidências favoráveis e contrárias às suas premissas básicas. Um dos primeiros e maiores experimentos tropicais sobre o efeito da fragmentação de habitats - também denominado nos meios científicos como "decaimento de ecossistemas" - foi implementado em 1979 na Amazônia Central, nas proximidades de Manaus. O Projeto Dinâmica Biológica de Fragmentos Florestais (PDBFF) foi concebido por Thomas Lovejoy e executado por cientistas ligados a várias instituições de pesquisa, sob a liderança do Instituto Nacional de Pesquisas da Amazônia (INPA). O projeto está em andamento ainda hoje, produzindo muita informação e ajudando a formar cientistas brasileiros e de outros países na área de conservação da biodiversidade. É o maior e mais longo experimento desse tipo no mundo.

A teoria de biogeografia de ilhas e os estudos sobre decaimento de ecossistemas influenciaram também à criação da nova disciplina de biologia da conservação, sobretudo fornecendo as bases teóricas para modelar reservas e áreas de proteção da biodiversidade. Por outro lado, muita polêmica foi gerada sobre como seriam as formas mais eficientes de conservação em contextos diferenciados, tendo se formado diferentes facções de pesquisadores e ambientalistas. A principal polêmica girou em torno 


\section{Sustentabilidade em Debate}

da sigla em inglês $S L O S S$, que pode ser traduzida em português pela pergunta: Qual a melhor estratégia de definir áreas de proteção ambiental - uma única área grande ou várias áreas pequenas? Apesar das polêmicas, a biologia da conservação se desenvolveu amplamente durante as décadas de 1980 e 1990 e atualmente desponta como uma ciência aplicada de grande relevância. Os trabalhos desenvolvidos com base no modelo teórico da biogeografia de ilhas ajudaram a construir conceitos importantes como "população mínima viável" e "metapopulação", hoje comumente usados na disciplina.

Na finalização do livro, Quammen ressalta a diferença entre o nível padrão de extinção de espécies ao longo do tempo geológico e o nível que ocorre em eventos de extinção em massa, que acontecem quando a taxa de extinção ultrapassa em mais que o dobro a taxa de especiação e acarreta perdas significativas de biodiversidade. Na opinião de grande parte dos cientistas naturais, estamos vivenciando um evento de extinção em massa, de proporções nunca vistas antes e, se continuarmos nesse ritmo, a tendência é perder grande parte da diversidade, que, entre outras coisas, fornece suporte de sobrevivência à espécie humana. Sem toda a convicção necessária, o autor demonstra alguma esperança de que o ser humano consiga reverter o quadro atual. Fecha o livro com uma reflexão sobre as mudanças que vêm ocorrendo desde a segunda metade do século XIX até os dias atuais. Essa reflexão é fruto de uma viagem que faz às ilhas Aru (arquipélago formado por cerca de 95 ilhas na província das Ilhas Molucas, no leste da Indonésia), seguindo os caminhos percorridos por Alfred Russel Wallace. Por se tratar de um local muito isolado, faz um desabafo: "As coisas tristes e terríveis que aconteceram em outros lugares (...) - imperialismo biológico, destruição maciça de habitats, fragmentação, depressão endogâmica, perda de adaptabilidade, (...), decaimento de ecossistemas, cascatas tróficas, extinção, extinção, extinção - não ocorreram aqui. É provável que aconteça em breve. Até lá, porém, ainda há tempo. Se tempo for esperança, então há esperança” (p.682)

Não há dúvida de que o livro $O$ canto do dodô é uma experiência bem sucedida de trazer ao grande público informações e possibilidades de sensibilização sobre um tema que, embora seja atual, fica em geral restrito ao meio acadêmico. No entanto, a leitura seria menos cansativa se não fossem dados tantos detalhes e exemplos que, em alguns casos, fazem o leitor se perder. Numa versão mais enxuta, $O$ canto do dodô poderia ser considerado um instrumento eficaz para conscientizar o público geral sobre a necessidade de mudança de atitude frente à natureza, de forma a garantir a manutenção da biodiversidade em níveis aceitáveis e mesmo a sobrevivência da espécie humana no longo prazo.

$$
* * *
$$


